ISSN: $1130-3743$

\title{
PRÁCTICAS PARA EL DESARROLLO MORAL EN UNIVERSITARIOS
}

\section{Practice for moral developpement in university students}

\section{Programme pour le développement moral chez des universitaires}

\section{Carmen NuÉvalos Ruiz}

Universidad de Valencia. Facultad de Filosofía y Ciencias de la Educación. Departamento de Teoría de la Educación. Avda. Blasco Ibáñez, 30. 46020.

Valencia. Correo-e: carmen.nuevalos@uv.es

Fecha de recepción: diciembre de 2003

Fecha de aceptación definitiva: marzo de 2004

BIBLID [(1130-3743) 15, 2003, 95-127]

RESUMEN

Este artículo presenta una investigación que ha consistido en la elaboración y puesta en práctica de un programa de educación moral. La intervención se ha orientado al desarrollo del razonamiento moral en un grupo de jóvenes universitarios, y su diseño se inspira principalmente en la teoría de Kohlberg. Prestamos una especial atención a la práctica de la educación moral.

Nuestros objetivos han sido, por un lado, entrenar a los alumnos en técnicas de desarrollo moral de cara al desempeño de su futura profesión docente. Por otro, incrementar su nivel personal de reflexión y desarrollo moral. Para la evaluación del programa hemos utilizado un método cuantitativo completado con información de tipo cualitativo.

Palabras clave: educación moral, práctica, evaluación cuantitativa y cualitativa, formación del profesorado, pensamiento moral. 
SUMMARY

This report presents an investigation that elaborates and puts a moral education programme into practice. The intervention has been directed to develop the moral reasoning in a group of university students. Its design is founded principally in Kohlberg's theory.

Our goals have been, on one hand, training the students in moral development techniques for their future teaching tasks. In the other, improving their personal reflection level and their moral development. The evaluation of the programme has been made using quantitative and qualitative methods.

Key words: moral education, practice, quantitative and qualitative evaluation, teacher's training, moral reasoning.

\section{SOMMAIRE}

Cet article présente une recherche qui a consisté en l'élaboration et la mise en pratique d'un programme d'éducation morale. Le travail est orienté vers le développement du raisonnement moral chez un groupe de jeunes universitaires en s'inspirant surtout de la théorie de Kohlberg. On vise surtout la pratique de l'éducation morale.

Nos buts sont, d'un côté, l'entrainement des élèves aux techniques de développement moral en vue de leur prochain métier d'enseignants, de l'autre côté, il s'agit d'accroitre leur niveau de reflexion et de développement moral. Pour l'évaluation du programme nous avons utilisé une méthode quantitative complétée d'une information qualitative.

Mots clef: éducation morale, pratique, evaluation quantitative et qualitative, formation des professeurs, pensée morale.

\section{TEORÍA Y METOdOLOGÍA DEL DESARROLLO MORAL DE KOHLBERG}

\subsection{Introducción}

El interés global de nuestro estudio es la moralidad humana y su desarrollo en un sentido global, si bien la intervención se inspira en la teoría de Kohlberg que estudia específicamente la dimensión cognitiva de la moralidad. Sin duda, Kohlberg, seguidor de Piaget, ha aportado una de las teorías más consolidadas y productivas respecto al desarrollo moral; sin embargo, situar la práctica de la educación moral en la perspectiva kohlbergiana exclusivamente puede conducir a un reduccionismo cognitivista. La maduración moral intelectual es condición necesaria pero insuficiente para lograr una maduración global de la conciencia. Saber qué es lo correcto y entenderlo no garantiza ni una conducta correcta, ni unas tendencias emotivas acordes con lo correcto. En educación el objetivo de la reflexión 
sobre la ética no es científico, ni filosófico sino práctico, queremos comprender mejor la ética para hacer mejores a las personas y sus actos (Hagnes, 2002).

Defendemos, por ello, que la educación de la moralidad afecta, es afectada y debe afectar a la totalidad de la persona. Juan Escámez propone los cinco ámbitos de los que tiene que ocuparse la educación moral: la conducta, el carácter, los valores, el razonamiento y el sentimiento (Escámez, 1999). Esta pretensión compartida por expertos, se consolida progresivamente como una educación total o global que es considerada como el nuevo paradigma educativo para el siglo XXI y que se orienta a las cuatro dimensiones de la educación holista: ciencia, sociedad, ecología y espiritualidad (Yus, 2001; Cortés, 2002). Existe en efecto una tendencia a proponer alternativas que ofrezcan una síntesis entre "la imagen de un sujeto aislado y autosuficiente y la de un sujeto diluido en el interior de las estructuras sociales. Sujeto y medio forman una unidad" (Puig Rovira, 2003, 51-52).

Por tanto, la teoría de Kohlberg dedicada al razonamiento moral atiende sólo parcialmente al desarrollo moral personal y debería completarse en la práctica escolar con otros contenidos teóricos y prácticos. Pero también entendemos que, pese a sus lagunas e insuficiencias, ha sido y continúa siendo de gran utilidad para la investigación y la práctica de la educación moral escolar. Por todo ello nos ha parecido una buena base y punto de partida para nuestra intervención.

La mayor parte de las investigaciones originadas por este autor y su teoría se plantean describir el razonamiento moral en muestras de sujetos y analizar el influjo de diferentes variables (edad, sexo, estudios...) en el nivel de desarrollo del razonamiento moral. En menor cantidad, han sido llevados a cabo estudios con el objetivo de clarificar las relaciones entre el razonamiento moral y otras dimensiones de la moralidad tales como actitudes y conductas (Blasi, 1980; Kohlberg y Candee, 1992; Nuévalos, 1997; Nuévalos, 2003).

Kohlberg ha dado también pautas para fomentar el crecimiento moral a partir de programas educativos cuyo objeto es estimular el crecimiento del razonamiento moral en grupos de estudiantes. Se han llevado a cabo estudios, fuera y dentro de nuestro contexto cultural, que confirman la eficacia de las metodologías recomendadas por este autor para facilitar el desarrollo cognitivo moral. Nuestro estudio se sitúa dentro de esta tercera línea de investigación.

La mayor novedad aportada por nuestro estudio posiblemente sea que con el mismo modelo de intervención se pretende un trabajo simultáneo y a dos niveles: por un lado, los alumnos se entrenan en el aprendizaje de técnicas de desarrollo moral de cara al desempeño de su futura profesión docente y, por otro, este entrenamiento es práctico, experiencial y significativo para los mismos alumnos porque mediante esta metodología van incrementando su nivel personal de reflexión y desarrollo moral.

A continuación, y como primer apartado, presentamos una síntesis de los planteamientos metodológicos y de evaluación de Kohlberg. En segundo lugar, pasamos a describir el programa sobre desarrollo del pensamiento moral que hemos llevado a la práctica. Finalizamos exponiendo los resultados obtenidos tras 
la intervención y algunas conclusiones a las que nos conducen los datos obtenidos por nosotros. En diferentes momentos nos ha parecido oportuno ilustrar las reflexiones y conclusiones con algunos ejemplos tomados literalmente de experiencias y testimonios de los propios alumnos.

\subsection{Propuestas fundamentales en la psicología del desarrollo moral de Koblberg}

Pueden diferenciarse dos grandes marcos psicopedagógicos dentro de los cuales se ha generado en las últimas décadas la investigación sobre el fenómeno moral. En primer lugar, y con franco protagonismo, la teoría psicopedagógica de Kohlberg y Piaget, con clara influencia de la filosofía de Kant, al defender que una moral genuina se fundamenta en unos principios universales de justicia de aplicación imparcial. Otra línea de estudio del fenómeno moral tiene su origen en la versión británica del utilitarismo que representan Hume, Smith y otros, para quienes la empatía era un vínculo social necesario. Esta línea halla su expresión actual en la investigación sobre la empatía, la compasión, la ética del cuidado, el comportamiento altruista y el desarrollo moral prosocial (Hoffman, 2002; Sober y Wilson, 2000; Roche y Sol, 1998). Los estudios en este segundo enfoque se han orientado principalmente a las emociones y las conductas.

La teoria de Kohlberg ha dominado desde la década de los 60 y hasta los 80 el campo del desarrollo moral en psicología y pedagogía; paralelamente la filosofía moral de Kant y seguidores ha monopolizado durante ese tiempo la filosofía moral. Sin embargo, en la última década del siglo xx han surgido importantes cuestionamientos que han puesto en tela de juicio el enfoque kohlbergiano: "existe un creciente reconocimiento de que los estudios en psicología del desarrollo moral deben retornar a los fundamentos... hoy estamos viviendo en una época poskohlbergiana" (Campbell, 2001, 132). Sin duda, este modelo necesita modificaciones y ampliaciones, pero siempre es necesario para abordar el crecimiento moral y en general comprender el desarrollo y madurez personal, puesto que el razonamiento es una parte esencial de la moralidad (Cortés, 2002). Recordemos, antes que nada, sus presupuestos básicos.

La teoría del desarrollo del razonamiento moral de Kohlberg se sitúa en una orientación constructivista de la moral. Defiende el autor que el desarrollo del juicio moral supone la construcción autónoma de un sistema cognitivo cuyos criterios formales se dirigen hacia la racionalidad, la autonomía, la perspectiva social universal y el principio de justicia. El medio externo puede potenciar o frenar el crecimiento del razonamiento moral, pero no puede variar su orientación evolutiva.

El desarrollo moral significa la construcción progresiva por parte del sujeto de un sentido moral propio, aunque no exento de influencias externas. La estructura esencial de la moralidad, aunque es personal, evoluciona a través de estadios o etapas cuyos rasgos formales son semejantes en todos los sujetos y culturas. Es precisamente este análisis formal el que ha permitido a Kohlberg "demostrar unas 
tendencias regulares y universales en la evolución del pensamiento moral y distinguir tres niveles con dos estadios cada uno" (Kohlberg, 1992, 79):

a. Nivel preconvencional (estadios 1 y 2): la perspectiva social es concreta, individualista, caracterizada por el egocentrismo.

b. Nivel convencional (estadios 3 y 4): la perspectiva social supone respeto activo por la autoridad, el orden establecido por las expectativas familiares y sociales.

c. Nivel posconvencional o "de principios" (estadios 5 y 6): la perspectiva social es una orientación de contrato social o de principios universales anteriores a la sociedad.

\subsection{Los grupos de discusión de dilemas morales: una propuesta para la educación moral}

Para promover el crecimiento del juicio moral en la práctica escolar, Kohlberg propone como metodología básica la técnica de los "grupos de discusión de dilemas morales". Esta dinámica permite explorar desde la razón las bases de la moral personal y colectiva, e ir clarificando y configurando un significado ético personal. Los alumnos no sólo manifiestan su adhesión a ciertos valores sino que el dilema deja al descubierto el sistema o estructura de valores propio y el de los demás. La propuesta de esta técnica se basa en la creencia de que la interacción entre los estudiantes acelera el desarrollo natural del juicio moral al exponerlos a conflictos morales planteados en los dilemas reales o hipotéticos que se plantean en la discusión.

La práctica de esta estrategia está fundamentada en una serie de factores que afectan positivamente al desarrollo del juicio moral:

a. Ofrecer oportunidades de toma de rol. Las oportunidades de toma de rol garantizan al sujeto puntos de vista conflictivos que le inducen a buscar una solución para alcanzar un equilibrio entre lo que percibe desde fuera y sus organizaciones internas.

b. Promover el desequilibrio mediante el conflicto cognitivo-moral. La función del conflicto es obligar al estudiante a una reorganización y reestructuración en el nivel inmediato superior de razonamiento moral. Además, el conflicto se produce también al exponer a los estudiantes menos avanzados en sus razonamientos morales a los argumentos de los estudiantes más avanzados.

c. Atmósfera sociomoral. En la configuración del sentido de la justicia en la conciencia individual es esencial la atmósfera social de los entornos en que se mueve el sujeto.

En la formación de grupos es recomendable "tener en cuenta el "tratamiento +1 ", que consiste en formar grupos cuyos individuos tengan niveles de juicio moral distintos $y$, concretamente, que la diferencia sea de un estadio, para que los argumentos 
de los más avanzados provoquen conflicto cognitivo-moral en los menos avanzados" (Adell, 1991, 234). El proceso debería iniciarse realizando un diagnóstico del nivel de desarrollo del juicio moral de los sujetos. Para ello pueden utilizarse alguno de los instrumentos que se describirán más ampliamente en el apartado dedicado a la evaluación de la moralidad. Entre ellos destacamos dos: la entrevista semiestructurada de Kohlberg y el Defining Issues Test (DIT de J. Rest).

\subsection{La evaluación de lo moral. Conveniencia de la evaluación de lo moral}

Durante décadas, al debate sobre la integración de la educación moral en la educación formal se le ha sumado el debate concreto respecto a la posibilidad y conveniencia de la evaluación de las diferentes dimensiones de la moralidad. Evaluar valores y actitudes se ha considerado peligroso porque implicaría juzgar moralmente a otras personas, y esto podría parecer ilegítimo si se defiende la pluralidad ético-moral. La evaluación, sin embargo, constituye un elemento central, alo que no se evalúa se devalúa (Bolivar, 1995, 11). No se trata de medir, sancionar o clasificar a los alumnos, sino sobre todo de destacar el carácter formativo de la evaluación: proporcionar continuamente información y datos al investigador, a los profesionales y a los alumnos para que tomen conciencia del propio y ajeno desarrollo y tomen las decisiones oportunas. "Cuando la evaluación abandona su propósito de control se convierte en un elemento de investigación del proceso de enseñanza, orientado a la mejora curricular y profesional de los profesores" (Bolívar, 1995, 112).

No ignoramos las dificultades con las que nos encontramos a la hora de llevar a cabo una evaluación sobre el pensamiento moral; consideramos, sin embargo, la conveniencia de establecer algún tipo de criterio y utilizar herramientas adecuadas para ello.

La información a partir de pruebas de tipo cualitativo es aconsejable, e incluso imprescindible, si deseamos evaluar no sólo los resultados sino también los procesos en la formación. Dado que tanto la evaluación cuantitativa como la cualitativa ofrecen información necesaria para la mejora de la calidad, progresivamente ambos enfoques se van acercando, viéndose más como complementarios que como puntos de vista opuestos.

\subsubsection{La evaluación del razonamiento moral: el método "abductivo"}

Los instrumentos de medida de lo moral en la década de los noventa miden en gran parte variables cognitivas y, en especial, el juicio o razonamiento moral. "Los instrumentos más utilizados son la Entrevista sobre el Juicio Moral (MJI) de Kohlberg y el Cuestionario sobre Problemas Sociomorales (DIT) de J. Rest" (PérezDelgado, Mestre y Escrivá, 1995, 14-15). 
Kohlberg y seguidores, en base a los principios piagetianos, se mueven lejos de los procedimientos psicométricos tradicionales. Aunque parten de la teoría de los estadios estructurales, las características de los estadios no vienen dadas por el investigador sino que son ofertadas por los sujetos. La pretensión de Kohlberg es que el instrumento haga surgir las estructuras subyacentes al pensamiento de los sujetos. En otros términos, las estructuras se infieren a partir de los argumentos esgrimidos por los testados: "las estructuras que nosotros tratamos de extraer en la construcción del test y a las que llegamos en la puntuación del test se abstraen de las respuestas así como de su forma y calidad" (Kohlberg, 1992, 383).

Localizar una estructura de estadio exige no un método inductivo sino abductivo que "requiere un trabajo en dos sentidos, entre supuestos teóricos tales como las estructuras postuladas, por un lado, y las reflexiones empíricas de esas estructuras dentro de las respuestas que los sujetos dan, por otro lado" (Kohlberg, 1992, 383). También Loevinger dice que el que construye los test encuentra estructuras evolutivas, no por un método inductivo sino por un método "abductivo", una especie de "mutuo atar con correas" que lleva consigo un continuo ir y venir entre las reflexiones teóricas y las respuestas que los sujetos dan (Loevinger, 1969). Puede decirse que la lógica de elaboración de los instrumentos de evaluación del juicio moral se asemeja más a la lógica dialéctica o de espiral de ciertos métodos cualitativos (tales como la investigación-acción) que a la lógica psicométrica de los tests tradicionales de inteligencia o personalidad.

\subsubsection{La entrevista semiestructurada de L. Kohlberg}

La entrevista del desarrollo moral ha sido el método de valoración más utilizado por Kohlberg. Consiste en una conversación entre entrevistador y entrevistado sobre la solución de tres dilemas morales. El entrevistador es, en último término, el responsable de la evaluación del estadio moral del sujeto. El objetivo de la entrevista es la obtención de respuestas cuantificables en cada cuestión. Para ello se proponen preguntas específicas a cada problema. Unas son optativas, otras han sido diseñadas para revelar el tipo y estadio del sujeto y otras están destinadas a iluminar la teoría ética del sujeto.

El sistema de puntuación permite que los sujetos sean clasificados según las categorías de Kohlberg y aparezcan asignados al nivel preconvencional (estadios $1,1 / 2,2$ ), al nivel convencional (estadios $2 / 3,3,3 / 4,4$ ) y al nivel posconvencional (estadios $4 / 5$ y 5 ).

1.4.3. Nuestro instrumento de evaluación del razonamiento moral: el Defining Issues Test (DIT) de J. Rest

El razonamiento o juicio moral consiste en el proceso por el que una persona selecciona un curso de acción como el mejor moralmente. El DIT, instrumento 
utilizado en nuestro estudio, intenta poner de manifiesto las estructuras de razonamiento moral subyacente al pensamiento de los sujetos, partiendo de la inducción a la selección de juicios específicos. En ese proceso incluimos tanto la sentencia por la que se determina que una acción es buena o mala, como también el argumento o razón que avala esa sentencia. Como es habitual, utilizaremos indistintamente juicio y razonamiento para referirnos a este proceso cognitivo.

El DIT es un instrumento de medida objetivo en forma de cuestionario. Está pensado para evaluar el nivel de razonamiento moral en que se encuentra el individuo según los estadios de Kohlberg. En el cuestionario se presentan seis historias («Enrique y el medicamento", "La ocupación de los estudiantes", "El preso evadido", "El dilema del doctor", "El Sr. Gómez" y "El periódico") que plantean problemas sociomorales. El sujeto ha de tomar una decisión en cada una de las historias; evaluando a continuación doce cuestiones que se le presentan por cada historia. Las cuestiones se encuentran ubicadas en los distintos estadios. En buena lógica y, si el sujeto entendió la estructura del cuestionario, se espera que preferirá aquellas cuestiones diseñadas según su propio nivel y estadio. Presuponemos además que éstas serán las cuestiones más valoradas y las que le han llevado a tomar sus decisiones. Por último, debe seleccionar las cuatro cuestiones más importantes de cada dilema. En función de las respuestas obtenidas y su valoración se mide la puntuación que tiene el sujeto en cada estadio. La puntuación permite situar a los sujetos en un continuo de seis estadios jerarquizados del desarrollo del juicio moral.

Dada la edad de los sujetos a los que se les aplica el cuestionario, el nivel 1 está casi totalmente ausente; por ello el DIT sólo mide a partir del estadio 2 de Kohlberg; las respuestas de los sujetos se adscriben a seis estadios (2, 3, 4, 5A, 5B y 6).

Con el DIT se obtiene además la puntuación $\mathrm{P}$, que mide los estadios posconvencionales en conjunto (5A, 5B y 6). Esta puntuación se considera la más importante, porque el DIT está especialmente diseñado para medir el razonamiento posconvencional. Sólo indirectamente este cuestionario nos informa del pensamiento convencional y preconvencional, es decir, de los niveles y estadios inferiores.

El Dit puede ser aplicado de ordinario a partir de los 13-14 años. El test puede ser administrado colectivamente, lo cual supone una ventaja importante. El tiempo necesario para responderlo es normalmente entre 30-50 minutos. El tiempo no es un factor a valorar, si bien, y por lo general, los sujetos de mayor edad y formación suelen emplear más tiempo en su cumplimentación.

\section{Programa Para el DesarRollo Del Pensamiento moral}

\subsection{El programa}

La experiencia que presentamos se ha orientado específicamente al desarrollo del razonamiento moral en un grupo de jóvenes estudiantes de Magisterio. Como ya se ha dicho, el diseño del programa se inspira principalmente en la teoría del desarrollo del razonamiento moral de Kohlberg. Nos ha orientado, entre otros, el 
supuesto de que el aula, al igual que otros contextos como el familiar, es ámbito que posee una idoneidad singular para educar la conciencia moral, dado que por naturaleza es lugar de encuentro entre lo individual y lo social. Además, el aula permite una interacción entre aprendiz y experto y, lo que es más importante, dentro de esta teoría, una interacción entre iguales.

\subsection{Objetivos del programa}

Nuestro trabajo se ha llevado a cabo dentro de la asignatura "Pedagogía de los Valores y las Actitudes" de la diplomatura de Magisterio. Nos hemos propuesto tanto fomentar el desarrollo moral personal de los estudiantes, como mejorar su cualificación profesional en el ámbito de la educación moral. Es decir, nuestra meta se ha orientado tanto a promover un desarrollo moral global en nuestros actuales alumnos, como contribuir a su capacitación profesional para que ellos mismos en un futuro sepan diseñar programas para el desarrollo moral. Si bien esto último no ha sido objeto de evaluación cuantitativa, sí ha sido tenido en cuenta en información recabada de forma cualitativa. Cabe concretar los objetivos específicos de la intervención de forma más sistemática como sigue:

a. Desarrollar las capacidades que conforman la conciencia moral del universitario y en concreto incrementar su nivel de razonamiento moral, mediante la discusión y la exposición a puntos de vista opuestos o diferentes al suyo.

b. Verificar la eficacia de la técnica "grupos de discusión de dilemas morales" en la estimulación del desarrollo del razonamiento moral.

\subsection{Metodología}

Numerosos estudios dentro y fuera de nuestro contexto cultural han mostrado la eficacia de los programas de educación moral dentro de la perspectiva sociomoral de Kohlberg. Se han llevado a cabo intervenciones según diferentes tipos de programas de educación moral. La técnica más utilizada es la que utiliza programas que enfatizan la discusión entre iguales sobre dilemas morales. Tenemos, por otro lado, las intervenciones denominadas "estimulación del desarrollo personal", que inciden sobre el desarrollo personal y social del sujeto. Éstas incluyen actividades experienciales y de reflexión. Por último, se han llevado a cabo programas de "cursos académicos" que, como su nombre indica, están centrados en contenidos académicos sobre temas humanísticos o temas sociales actuales.

El análisis comparativo de las diferentes intervenciones llevadas a cabo en este campo pone de manifiesto que los programas basados en la discusión de dilemas morales son los que manifiestan, como media, una mayor progresión, seguidos de los programas de desarrollo personal. Los centrados en contenidos académicos, sin embargo, no manifiestan efecto alguno, con resultados inferiores incluso a los grupos control (Pérez-Delgado y Mestre Escrivá, 1995, 169-170). 
El modelo seleccionado para nuestro programa de desarrollo moral ha sido el primero, es decir, se centra en los grupos de discusión entre iguales sobre problemas morales. Consecuentemente, la técnica aplicada en nuestra intervención ha sido principalmente "el debate de dilemas morales", si bien combinada con otras metodologías y técnicas complementarias.

El debate de dilemas es una técnica que se fundamenta en la idea de que las estructuras del pensamiento moral pueden estimularse mediante la exposición de un modelado entre iguales, presentando a los sujetos de niveles inferiores los argumentos que exhiben otros sujetos con niveles superiores de razonamiento moral. No se trata de una copia de lo que piensan los sujetos más evolucionados, sino de proveer experiencias cognitivo-morales que facilitan la progresión natural del juicio moral.

\subsection{Hipótesis}

Esperamos que, como consecuencia de la aplicación del programa, se producirá una evolución significativa en el juicio moral de los sujetos participantes, según es definido en la teoría de Kohlberg.

El crecimiento del nivel de pensamiento moral se manifestará operativamente en un aumento del razonamiento en el nivel posconvencional. Este aumento conllevará una disminución paralela en los niveles preconvencional y convencional.

\subsection{Muestra y composición del grupo}

La asignatura optativa "Pedagogía de los Valores y las Actitudes" nos ha ofrecido el tiempo y espacio idóneos para la aplicación del programa, que ha tenido lugar durante el curso académico 2002-2003, durante los meses de octubre-diciembre.

El número de los matriculados en el grupo fue de 39 alumnos. El grupo de intervención incluyó 29 participantes en el programa a tiempo completo. De éstos se han excluido de la evaluación a cinco sujetos, dos por no entregar el cuestionario en el plazo fijado y tres por haber sido halladas importantes inconsistencias en las respuestas.

En la muestra definitiva, por tanto, han sido considerados 24 alumnos. De ellos 23 son mujeres y uno varón. Dos datos destacan: respecto al sexo que el grupo está compuesto casi en su totalidad por mujeres. Por otro lado, y por lo que respecta a la edad, han obtenido una media de 23 años. Teniendo en cuenta que el grupo corresponde a un $2^{\circ}$ curso de Magisterio, puede decirse que la edad media cronológica es superior a lo normal. Además, existe una gran variabilidad entre 19 años la de edad inferior y 52 la de edad superior. 


\subsection{Duración del programa}

El programa duró dos meses, estando compuesto por 12 sesiones. Cada sesión ocupó aproximadamente 1 hora y 45 minutos, con una periodicidad aproximada de dos sesiones por semana. La intervención, en cuanto a su longitud temporal de ocho semanas, pertenece al grupo de "programas de duración media". Los datos de que disponemos indican que los programas de duración inferior a las tres semanas no manifiestan progresión favorable alguna, mientras que los de duración media (entre 4 y 12 semanas) y larga duración (entre 13 y 28 semanas) producen efectos parejos.

\subsection{Diseño de la intervención}

La intervención ha seguido el clásico esquema pretest-postest. Como es sabido, este modelo de intervención supone en primer lugar la evaluación de la variable que es objeto de estudio. La variable estudiada por nosotros es el razonamiento moral y nuestro instrumento de medida ha sido el DIT de J. Rest, ya descrito con anterioridad. Así pues, la intervención se inicia con la cumplimentación por parte de los sujetos del DIT, con ello analizamos el perfil del pensamiento moral de nuestros sujetos antes de empezar el programa.

A continuación, se siguen las sesiones dirigidas a incrementar pedagógicamente el nivel de desarrollo del juicio moral de los sujetos; en nuestro caso, la presentación del dilema y su posterior discusión. Algunas de las sesiones incluyeron, además del debate moral, la presentación de conceptos o bien la realización de actividades pertinentes dentro y fuera del aula. A lo largo de todo el proceso el profesor inicia, guía y concluye la discusión. Cuando las sesiones de intervención han concluido, y para comprobar la eficacia de las sesiones de intervención, se vuelve a evaluar el nivel de razonamiento moral que manifiestan los sujetos tras haber participado en el programa para constatar si ha habido diferencias significativas que pueden atribuirse a la intervención.

3. DESCRIPCIÓN DEL PROGRAMA DE INTERVENCIÓN PARA EL DESARROLLO DEL PENSAMIENTO MORAL: CONTENIDOS T'RABAJADOS Y ACTIVIDADES REALIZADAS

Básicamente, nuestra intervención se ajustó a las fases ya descritas con anterioridad. Previamente al inicio de la puesta en práctica del programa, el grupo de alumnos fue consultado sobre ello y todos aceptaron participar y ser evaluados. Tras haber manifestado su interés en participar, se utilizó un refuerzo positivo, se les dijo que la evolución en el postest medida por el DIT sería recompensada en la nota académica. Pasamos a continuación a describir las fases seguidas en la puesta en práctica del programa: 


\subsection{Diagnóstico inicial}

El programa se inició con un pretest en el que se valoró el nivel inicial de desarrollo del juicio moral de los sujetos. Para ello se utilizó el Defining Issues Test (DIT de J. Rest). En la tabla 3 se presentan los resultados obtenidos en los tres niveles tras la corrección del cuestionario. Estos mismos resultados fueron mostrados al grupo de alumnos.

TABLA 1

RESULTADOS EN EL PRETEST OBTENIDOS EN ONTENIENTE EN LOS NIVELES DEL DIT

\begin{tabular}{|l|c|}
\hline Nivel & Onteniente pretest \\
\hline Preconvencional & 8,33 \\
\hline Convencional & 53,67 \\
\hline Posconvencional & 32,49 \\
\hline
\end{tabular}

Observamos a primera vista que la puntuación obtenida por el grupo de alumnos de Onteniente es superior en el nivel convencional $(53,67)$, en el que obtienen más del 50\% del total. Le sigue la puntuación en el nivel posconvencional $(32,49)$, con más de un $30 \%$. El dato inferior lo obtienen en el nivel preconvencional $(8,33)$, en el que no llegan a un $10 \%$. En líneas generales el perfil del pensamiento moral de los sujetos se ajusta al criterio normativo de la teoría de Kohlberg y también coincide globalmente con los datos ofrecidos en otros estudios con jóvenes y adultos. Sí hay que hacer notar, no obstante, que nuestros jóvenes son más convencionales y menos posconvencionales que otros grupos de características cronológicas y académicas semejantes (Pérez-Delgado y Mestre Escriva, 1999; Nuévalos, 1997).

Como se ha dicho y como fruto de la intervención, esperamos que esta tendencia se invierta a favor del pensamiento posconvencional y en detrimento del convencional y el preconvencional.

\subsection{Formación de grupos, elaboración de dilemas y creación del set apropiado}

La formación de grupos se ciñó al criterio básico de heterogeneidad y variabilidad. Los grupos de discusión fueron variando su composición con un número de alumnos entre 5 y 9.

Respecto a la elaboración de los dilemas, la profesora disponía de una serie de dilemas preparados, pero también se pidió a los alumnos que preparasen dilemas con vistas a dos objetivos. Por un lado, que los contenidos fueran referidos a temas que les implicasen y motivasen y, por otro, encomendarles una tarea académica que les ayudase a una mejor comprensión de la técnica y también de la teoría de Kohlberg. De hecho y puesto que el grupo participante estaba integrado en su totalidad por alumnos de Magisterio, se les pidió que elaborasen un dilema 
real o hipotético dirigido a adultos y otro adaptado y dirigido a niños. No debe olvidarse que la especialidad de nuestro grupo de estudiantes de Magisterio era "Infantil"; consecuentemente muchas de las técnicas, ejemplos y actividades que se llevaron a cabo se intentó adaptarlas a la etapa infantil. Podemos ver a continuación dos ejemplos de dilemas preparados por nuestros alumnos y cuyos contenidos estaban adaptados y dirigidos a niños:

TABLA 2

EJEMPLOS DE DILEMAS PREPARADOS POR LOS ALUMNOS, ADAPTADOS PARA NIÑOS

Tema del dilema: Relaciones sociales. Alumna: M. Carmen Puchades

Valores en conflicto: La solidaridad con los demás y amistad

En clase bay un niño que se lleva muy mal con mis amigos. A mi me cae bien, nunca me ba becho nada malo. Hoy nos bemos ido de excursión y sus amigos no ban venido. Está solo en el autobús y seguramente nadie le bará mucbo caso en todo el dia.

No sé si ir a sentarme con él o no. Si voy, mis amigos se sorprenderán y tal vez les siente mal. No se qué bacer.

Tema del dilema: Amistad. Alumna: Llanos Sanchís

Valores en conflicto: Integración o reconocimiento social y amistad

Un niño de la clase ba tenido piojos y desde entonces todos los niños de la clase se burlan de ély no quieren jugar con él excepto su mejor amigo. Pero las burlas también van bacia él. El resto de la clase le amenaza que si se junta con el piojero tampoco jugarán con él. El dilema que se plantea es si el niño sigue con su mejor amigo a pesar de las burlas $y$ amenazas, o le da de lado y se va con el resto de la clase.

Una gran ventaja para la aplicación del programa es que se llevó a cabo dentro de la asignatura "Pedagogía de Valores y Actitudes", con lo cual durante casi un mes el grupo estuvo trabajando sobre contenidos y técnicas dirigidos a la educación en valores. Las sesiones de trabajo teórico y aplicado que tuvieron lugar antes de la intervención despertaron sin duda el interés de los alumnos para profundizar y reflexionar de forma monográfica, tratando de forma específica el tema del desarrollo del pensamiento moral. Fueron sesiones introductorias que permitieron manejar unos conceptos y un lenguaje común que facilitó posteriormente la comprensión y aplicación.

Por otro lado, se les explicó a los alumnos la necesidad de crear un clima adecuado manifestando actitudes de libertad y espíritu crítico, pero al mismo tiempo de respeto y apertura a las aportaciones de los demás. En definitiva, los componentes y rasgos de un debate basado en la sinceridad y la escucha activa.

No obstante, hay que hacer notar que los alumnos de este grupo ya desde un principio se habían mostrado, tanto a nivel personal como en las dinámicas grupales, con un nivel de motivación, participación, responsabilidad y respeto poco comunes. Nosotros barajamos como una causa que jugó a nuestro favor la edad 
del alumnado (superior a la media de los estudiantes de Magisterio en otras extensiones universitarias) que deducimos y que apunta hacia una mayor madurez personal global.

\subsection{Sesiones de intervención}

La duración de cada sesión fue de una hora y cuarenta y cinco minutos. No es recomendable dedicar todo este tiempo exclusivamente a un debate. Por ello, se trabajó simultáneamente información, documentación y actividades acerca de los contenidos del programa de la asignatura. Se seleccionaron aquellos temas más relacionados con la teoría y metodología que nos ocupaba, sobre todo la teoría de Kohlberg. Los distintos dilemas fueron presentados con modalidades diferentes. Unas veces los mismos alumnos presentaban el dilema elaborado por ellos y votado en el grupo como el de mayor interés. Otras eran elaborados y presentados por la profesora. Por último, otros se plantearon a partir del visionado de alguna película o secuencia de película.

Es necesario que el grupo se ponga de acuerdo sobre los posibles cursos de acción del protagonista principal de la historia. Los expertos advierten de que entender deformadamente el dilema puede conducir a que los sujetos lo destrocen realizando "escapatorias"; es decir, ante la tensión que supone tomar una decisión, es normal que intenten escapar desvirtuando el problema, deformando la historia o mediante planteamientos generales y tópicos socialmente aprendidos que hagan que se pierda el sentido de confrontación del dilema. Se recomienda prever posibles "escapatorias" y no confundir éstas con un razonamiento moral genuino de niveles bajos.

En nuestra experiencia, sin embargo, hemos constatado que en algunos dilemas los alumnos, para evitar tomar una decisión que suponga perjuicio de algún modo para una de las partes, realizan un gran esfuerzo intelectual en la búsqueda de soluciones alternativas que no sean lesivas para nadie. En ocasiones las soluciones ofrecidas son ingeniosas, realistas y sensatas. Dejamos para otra ocasión el estudio más exhaustivo de esta búsqueda de alternativas, empeñadas en rechazar una solución que daña, y que, por el momento, hemos creído que era un modo de afrontar los dilemas más característico de las mujeres (Nuévalos y Bellver, 1999).

Pueden verse en la tabla 3 los diferentes dilemas que fueron seleccionados para ser finalmente debatidos en las sesiones del programa. 
Dilema 1. "La Ingeniera". Una ingeniera que trabaja en una fábrica descubre que dicha empresa está ocultando vertidos peligrosos a un río. Si descubre públicamente este becho o denuncia al director de la empresa, además de perder su trabajo, podría dejar sin trabajo a bastantes personas. ¿Qué debería bacer la ingeniera?

Dilema 2. "La caja de música”. En América un bombre anciano es acusado de baber cometido en su juventud espantosos crimenes contra la bumanidad durante la Alemania nazi. Su bija es abogado y él la convence para que lo defienda. La bija lo defiende intentando demostrar que la relación con el soldado nazi es una confusión, ella está totalmente convencida de la inocencia de su padre. Cuando la bija ya ba logrado prácticamente su absolución, descubre que en efecto su padre es responsable de todo lo que se le acusa. ¿Debería la bija denunciar al padre?

Dilema 3. "Los elefantes". El director de un parque nacional en Kenia tiene como responsabilidad esencial la protección y cuidado de unas manadas de elefantes, ya que este animal es una especie en peligro de extinción. Cercanas a los límites del parque están asentadas unas aldeas y granjas, la mayoria de ellas babitadas por personas muy bumildes cuyo único modo de subsistencia es el cultivo de sus tierras.

En los últimos meses una manada de elefantes ba traspasado los limites del parque en varias ocasiones irrumpiendo en los terrenos de algunos campesinos, destrozando sus cultivos y dañando incluso sus viviendas. En estas ocasiones el director ba invertido todo tipo de recursos para bacer volver a los elefantes al parque y lo ba conseguido; sin embargo, los elefantes parecen estar acostumbrándose a estas incursiones y cada vez son más continuas. Si bien el director consigue bacer volver a los elefantes al parque, todos los esfuerzos por impedir que salgan han resultado inútiles. Algunos campesinos, por otro lado, estarian decididos a matar a los elefantes que destruyan sus propiedades, pero temen a la legislación que, en este punto, es muy severa.

Entre las medidas que ba de tomar el director del parque debe decidir si priorizar la protección de las propiedades de los campesinos o la vida de los elefantes.

Dilema 4. "La novia infiel. Laura y Pilar son amigas. Pilar tiene novio, se llama Pedro. Una noche en que Laura está divirtiéndose en una discoteca ve a Pedro besándose con otra chica que no es Pilar. ¿Debería Laura decirselo a Pilar?

Dilema 5. "Infidelidad en un matrimonio". Alicia es una mujer casada, ella y su marido Juan son amigos de otro matrimonio, Inés y Alberto. Una noche en que Alicia y Juan están cenando con otros amigos ven a Alberto besándose con otra chica que no es Inés. Descubren que no es un lio de una nocbe. ¿Deberian decírselo a Inés?

Dilema 6. "La adopción". Un matrimonio tienen un bijo adoptado, babian decidido decírselo cuando tuviera 12 años, el niño ha cumplido la edad, pero atraviesa una crisis adolescente y sus padres adoptivos tienen miedo de que decirle la verdad complique las cosas. ¿Deberian decirle la verdad a su bijo o esperar? 


\begin{abstract}
Dilema 7. "La hija con espina bífida". Un matrimonio tiene una hija con espina bífida. Han buscado todo tipo de alternativas. En un centro les ban propuesto que la madre se quede embarazada y abortar para hacer un trasplante a su bija. Les ban dicho que existen bastantes posibilidades de que la operación salga bien y la niña con espina bífida pueda andar perfectamente el resto de su vida y llevar una vida normal. ¿Deberian aceptar la propuesta?
\end{abstract}

Dilema 8. "El Sr. Ansúrez". Las sirenas comenzaron a sonar. Todos se dieron cuenta que una bomba de bidrógeno iba a ser arrojada sobre la ciudad por el enemigo y que la única forma de sobrevivir era meterse en un refugio.

La familia Ansúrez se habia construido su propio refugio con viveres y aire suficientes para cuatro personas durante cinco dias. Sabian que, pasado este tiempo, la contaminación habria disminuido basta el punto de poder abandonar el refugio, pero, si salian antes, moririan. Sus vecinos no tenian refugio y quisieron entrar. Los Ansürez sabian que, si compartian el refugio, todos podian morir, y no les permitieron entrar. Los vecinos trataron de romper la puerta, Ansúrez cogió su rifle y los amenazó con disparar; pero ellos no se apartaron. ¿Tenía que dispararles o permitirles entrar?

Dilema 9. "Bailando con Lobos". El protagonista es un soldado del ejército americano. Su misión es vigilar un puesto que en realidad se halla abandonado y en el que se ha instalado. Con el tiempo el soldado va entablando una buena relación con una tribu india. En un momento dado los indios le preguntan por las intenciones del ejército, si es su intención adueñarse de las tierras donde viven los indios y expulsarlos. El soldado sabe que en efecto es asi. ¿Debe alertar a los indios siendo desleal con su pais y el ejército?

Dilema 10. "I.A. ¿Qué significa ser persona humana? ¿Puede o debe considerarse al "robot David" una persona?.. La pelicula empieza con la propuesta de construir un robot capaz de amar. El protagonista de la pelicula es David, un niño robot, al que una pareja ha adoptado. La pareja ba sido elegida para tener a David porque tienen un bijo que lleva varios años en coma y sin esperanzas de rehabilitación. David está diseñado para encariñarse y manifestar un afecto irreversible bacia la persona que grabe en él una impronta. La persona que la graba es su madre adoptiva. A partir de abi David exbibe una inteligencia superior a la bumana y además manifiesta un cariño incondicional bacia su madre. Poco a poco sus padres y en especial la madre también corresponden a David emocionalmente. En general David es respetuoso y cariñoso con todo el mundo; pero en un momento dado el bijo de la pareja despierta del coma y empiezan a surgir problemas con David, que llega, aunque sin ninguna malicia por su parte, a poner en peligro la vida del bijo. La madre se ve obligada a abandonar a David. A partir de aqui toda la película es la lucba de David por reencontrar a su madre.

Tras la presentación del dilema, cada alumno reflexionaba individualmente durante unos momentos y ponía por escrito su postura dando sus razones. Poner la opinión por escrito es un modo de forzar el ejercicio del juicio moral a nivel individual y la toma de postura personal. Este primer paso lo consideramos fundamental porque evita, además, que el alumno adopte una actitud absentista y se deje llevar por la opinión de otros, lo que impediría que la persona experimente el conflicto moral, para lo que es necesario que la opinión de otros colisione con 
la propia. Véanse en la tabla 4 algunos ejemplos de esta primera autorreflexión con la que se iniciaban el debate.

TABLA 4

EJEMPLOS DE ARGUMENTOS ESGRIMIDOS POR LOS ALUMNOS ANTE LOS DILEMAS

Dilema 1. "La Ingeniera"

Silvia Blanes: «Debería denunciar, porque la fuga provocaría daños mayores, daños a la salud de las demás personas. Si se cierra, provoca una crisis social pero es pasajera, porque toda la gente que despide posteriormente, cuando la fisura esté arreglada, la puede volver a contratar. El número de personas afectadas, al denunciar, será menor, porque probablemente las personas afectadas por la contaminación será mayor que las despedidas por la fábrica».

María Jesús Bustos: "Creo que la ingeniera debería denunciar el caso a la autoridad. Si yo fuera la ingeniera, preferiría que me despidieran a no tener en mi conciencia el mal acto de contaminar la zona. Un despido se puede solucionar con otro trabajo y duraría poco tiempo. La catástrofe tardaría años en volver a recuperar la vida diaria y económicamente sería un gasto innecesarion.

Dilema 3. "La caja de música"

Llanos Sanchís: "Debería denunciar los hechos, a pesar de ser una decisión difícil, porque debe pagar el daño que ha hecho a la sociedad, sobre todo a las víctimas y sus familias. Hay que intentar ser objetiva (tarea difícil tratándose de tu padre) y que prevalezcan los principios sobre los sentimientos por muy duro que resulte.

M. ${ }^{2}$ Ángeles Martínez: “Debería denunciarlo, ya que él es responsable de muchas muertes... tiene que pagar de algún modo o responsabilizarse de lo que ha hecho.

Pero en realidad no lo haría, no volvería a hablarle, pero no le denunciaría.

Dilema 8. "El Sr. Ansúrez"

Ana Mompó: «Considero que pensaría en mi familia, en mis hijos y creo que dispararía por salvarlos si fuera necesario; aunque sea una forma de pensar egoísta; creo que primaría el instinto de supervivencia".

Silvia Blanes: "El Sr. Ansúrez debería disparar porque peligraría la vida de su familia y la suya, y antes está la vida propia y la de su familia que la de los demás.

Pero yo no lo haría, yo me arriesgaría, los dejaría entrar e intentaría hacer lo posible para poder sobrevivirn.

Rebeca Agulló: "El Sr. Ansúrez debería disparar porque las personas que están con él son su familia y tiene que intentar salvarles a ellos primero que a nadie. También pienso que deberían disparar porque, si entran todos al refugio, probablemente no se salvará nadie y entonces es mejor que, al menos, se salve la familia Ansúrez que no que mueran todos".

Puede suceder que ya desde el primer momento no se produzca diferencia de opiniones y que exista un acuerdo unánime entre todos los sujetos. Lo recomendable en este caso es rechazar el dilema propuesto y plantear otro diferente. A modo de ejemplo, en nuestra intervención, cuando los alumnos eligieron para discutir el dilema de "la adopción", hubo un acuerdo casi total respecto a que los 
padres debían decírselo al hijo. Se llevaron a cabo varios comentarios durante unos minutos y seguidamente la profesora planteó el dilema de "la hija con espina bífida".

Sin embargo, esto no siempre y necesariamente debe ser así. En efecto, entendemos que en ocasiones, aunque el debate no sea posible por el contenido, sí puede estimularse el coloquio. Pese a estar de acuerdo los alumnos, cuando coloquian ofrecen argumentos ubicados en estadios diferentes y puede el profesor estimar conveniente y enriquecedor que sean exhibidos los argumentos de los niveles y estadios superiores. Éste fue el caso cuando se planteó el dilema «Bailando con Lobos". En este dilema hubo un acuerdo prácticamente unánime, los alumnos consideraban "...que el soldado debería decírselo a los indios..... Pero veamos y comparemos dos ejemplos en los que se pone claramente de manifiesto que decisiones morales similares pueden dar lugar o apoyarse en juicios morales diferentes:

Alumno 1: "Creo que Kevin Cosner sí que debería contárselo a los indios porque le ha costado bastante relacionarse con ellos y hacerse amigo de ellos. Por eso pienso que debe respetar la amistad antes que los deberes del trabajo...".

Alumno 2: "Pienso que el soldado debería decírselo a los indios porque el soldado está en tierras de los indios y éste se tiene que adaptar a los indios. Poco a poco el soldado se ha dado cuenta de que los indios no son como pensaba y acaba relacionándose con ellos. Si no tuviera relación con los indios, también pienso que debería decírselo porque ellos están en sus territorios y tienen derecho a defender sus tierras".

Véase que la misma decisión se apoya en razonamientos bien distintos. El primero, que apela a la amistad, se sitúa en el nivel convencional, concretamente en el estadio 3, que viene definido por un punto de vista moral que ha evolucionado a una perspectiva moral que busca la "satisfacción de expectativas de grupos sociales próximos". Sin embargo, el alumno 2 apela, para fundamentar su juicio moral, a los derechos de los indios. Nos encontramos, por tanto, ante una perspectiva moral "del contrato social y los derechos individuales" propia del estadio 5 en el nivel posconvencional.

En los cinco primeros dilemas el debate se llevó a cabo primero en pequeño grupo y luego en gran grupo. Posteriormente y, tras plantear el dilema, los mismos alumnos insistieron en pasar directamente a la discusión en gran grupo. La sugerencia fue aceptada porque el debate en el grupo-clase tenía un buen nivel de reflexión y participación.

Como queda dicho, el objeto de la discusión en grupo es facilitar el desequilibrio cognitivo-moral, esperando con ello un incremento de la madurez en el pensamiento moral de los alumnos. En consecuencia, el papel del profesor durante la discusión fue velar para que se genere el debate entre "los menos y los +1 estadio". Así, por ejemplo, en el debate "La novia infiel" uno de los argumentos más barajado por los alumnos fue: "yo se lo diría si el engañado es mi amigo porque si es amigo tuyo no merece que lo engañen. Ningún alumno contradecía dicha argumentación porque en esa afirmación parecían estar todos de acuerdo. 
Como puede verse, el argumento se sitúa en el estadio 3 que, como se ha dicho, está caracterizado por un punto de vista moral de "satisfacción de expectativas de grupos sociales próximos". Puesto que el debate parecía estancarse en el nivel convencional y concretamente en el estadio 3, el papel de la profesora fue generar conflicto no tanto dando argumentos de nivel superior, sino planteando la pregunta "y si no es tu amigo, ¿merece que lo engañen?". Esta cuestión puso de manifiesto la contradicción implícita en el argumento e incitó a reflexionar en un nivel superior.

Con todo, la profesora intervenía lo menos posible y a veces estimulaba el debate preguntando al azar a sujetos concretos. Hay alumnos más tímidos que agradecen una pregunta directa. Otras veces la profesora incitaba a exponer sus argumentos a personas que ya habían mostrado unos juicios ubicados en el nivel posconvencional, forzando a centrar la atención en un argumento de tipo posconvencional cuando el calor del debate impedía que todos escucharan. O bien preguntando a los alumnos posconvencionales para que clarificaran sus razonamientos y dar la oportunidad al resto de compañeros de una mayor comprensión de las razones manifestadas.

Normalmente de forma natural se producía enseguida el debate entre los sujetos de niveles inferiores y los de niveles superiores

Deseamos hacer un breve comentario a propósito del influjo de los contenidos en la estructura o dimensión formal del pensamiento moral. No es el momento de entrar en el debate llevado a cabo en el marco de la teoría de Kohlberg sobre este tema. Por nuestra parte disponemos de documentación y datos que avalan ampliamente este influjo, aunque aún no han sido objeto de un grado suficiente de elaboración que nos permita su publicación.

Por el momento, sólo deseamos hacer notar una observación nuestra. Indudablemente los alumnos esgrimían argumentos situados en diferentes niveles y estadios según fuera el tema planteado. Si el dilema les afectaba de un modo emocional y personal, sus argumentos tendían a situarse en un primer momento en el nivel convencional y sobre todo en el estadio 3. Cuando el dilema iba referido a cuestiones relacionadas con la justicia social, ofrecían, ya desde el principio, razonamientos más posconvencionales.

\subsection{Evaluación final}

La evaluación final consistió, por un lado, en el pase del DIT; los resultados se verán con detalle en el apartado siguiente. No obstante, a la hora de valorar el desarrollo moral y cómo influye en él una metodología educativa, es insuficiente adoptar un prisma cuantitativo y numérico y exclusivamente dirigido a los resultados. Por esta razón, además de la evaluación cuantitativa que nos ofrece el cuestionario de problemas sociomorales, hemos intentado triangular el diagnóstico con puntos de vista diferentes y métodos diferentes. 
Nuestro interés no era tanto medir o clasificar a los alumnos, sino sobre todo obtener información respecto a en qué medida nos aproximamos a los objetivos propuestos, si los valores que trabajamos están siendo incorporados y el pensamiento moral se está desarrollando. Hemos intentado valorar en qué medida el juicio moral de los alumnos evoluciona en el sentido pronosticado; pero además, si ese aprendizaje moral lo aplican de algún modo a su propia realidad.

Por otro lado esa misma evaluación del alumno es también una evaluación de la propia intervención. En efecto, cuando se investiga sobre la acción educativa, la misma actividad educativa debe ser evaluada pasando así a convertirse en investigación. En definitiva, se ha evaluado tanto el proceso de aprendizaje de los alumnos como el propio programa. Y ello con una medida objetiva y también con medidas subjetivas: el criterio de las propias alumnas.

Así pues, la información obtenida a partir del DIT se ha completado con otro tipo de información derivada de técnicas cualitativas de evaluación. A tal efecto se realizaron las siguientes actividades:

1. Se grabó una sesión en la que se llevó a cabo una asamblea de aula para la valoración de las clases y específicamente de la intervención.

2. Se pasó un cuestionario con una pregunta de respuesta abierta. La pregunta iba dirigida a los aprendizajes de tipo "adulto" realizados tanto a lo largo de la propia vida como aprendizajes de tipo "adulto" realizados en la asignatura.

3. Por último, disponemos también de información obtenida a partir de cuestionarios anónimos de preguntas abiertas, semiabiertas y cerradas.

En la tabla 5 exponemos un ejemplo de respuesta dada por una alumna al cuestionario de "respuesta abierta" sobre aprendizaje adulto.

TABLA 5

EJEMPLOS DE RESPUESTAS AL CUESTIONARIO SOBRE APRENDIZAJE ADULTO

Marta Bataller: "A través de los temas que hemos tratado con los dilemas he aprendido cosas que luego puedo aplicar a mi vida. A través de los dilemas, me he llegado a plantear cosas que de otro modo no hubiera hecho".

Las características y normas a las que debe ajustarse este trabajo, respecto al tiempo y al espacio, no permiten ampliarlo con un análisis y estudio más exhaustivo de la información obtenida a partir de las pruebas cualitativas de evaluación. Los resultados obtenidos serán presentados en otro momento. 


\section{RESULTADOS DE LA INTERVENCIÓN, COMENTARIOS Y CONCLUSIONES}

\subsection{El razonamiento moral de los sujetos}

Veamos en primer lugar los datos generales del razonamiento moral de los jóvenes objeto de estudio, según las puntuaciones que obtuvieron antes de la intervención. En la tabla 9 se presentan los resultados obtenidos en los tres niveles del Defining Issues Test. En la segunda columna aparecen las puntuaciones obtenidas tras la primera valoración del nivel de desarrollo del juicio moral de los alumnos. En la tercera columna pueden verse los rasgos que caracterizan la perspectiva social adoptada en cada nivel según la teoría de Kohlberg.

A la vista de todo ello hay que decir que los sujetos se sitúan preferentemente en el nivel convencional, que obtiene más del $50 \%$ de la puntuación, exactamente un 53,67\%, seguido por el posconvencional en el que obtienen un 32,49\%. Por último, obtienen una puntuación muy inferior a las anteriores en el nivel preconvencional, un $8,33 \%$.

No hay que olvidar que, aunque el desarrollo del nivel convencional tiene lugar en la etapa adolescente, sin embargo, es también el que caracteriza mayoritariamente la juventud y la etapa adulta. En efecto, el estadio 3 se empieza a desarrollar durante la adolescencia y, junto con el 4, permanece como el más elevado para la mayoría de adultos de nuestra sociedad. "No obstante, otra característica definitoria de la etapa adolescente y de la adulta es también la aparición y consolidación en mayor o menor grado, pero de forma relevante, del pensamiento posconvencional" (Nuévalos Ruiz, 1997, 183).

TABLA 6

RESULTADOS OBTENIDOS EN LOS NIVELES DEL DIT EN EL PRETEST

\begin{tabular}{|l|c|l|}
\hline Nivel & $\begin{array}{c}\text { Onteniente } \\
\text { pretest }\end{array}$ & $\begin{array}{l}\text { Perspectiva social que caracteriza el } \\
\text { nivel }\end{array}$ \\
\hline $\begin{array}{l}\text { Preconvencional } \\
\text { (estadio 2) }\end{array}$ & 8,33 & $\begin{array}{l}\text { Perspectiva social concreta } \\
\text { individualista, egocentrismo }\end{array}$ \\
\hline $\begin{array}{l}\text { Convencional } \\
\text { (3 y 4) }\end{array}$ & 53,67 & $\begin{array}{l}\text { Perspectiva social de "miembro de la } \\
\text { sociedad" }\end{array}$ \\
\hline $\begin{array}{l}\text { (Posconvencional } \\
\text { puntuacion P\%) }\end{array}$ & 32,49 & $\begin{array}{l}\text { Busca principios morales con } \\
\text { aplicación universal }\end{array}$ \\
\hline
\end{tabular}

Siendo inferior la puntuación obtenida en el nivel posconvencional que la obtenida en el nivel convencional, no es en absoluto desechable, es sin lugar a dudas un porcentaje relevante. Lo que significa que, con frecuencia, los jóvenes han desechado argumentos que intentan solucionar los problemas morales desde posturas convencionales o de "buenos chicos" optando en su lugar por la 
consideración de la igualdad entre sujetos que pertenecen a colectivos más allá de los grupos inmediatos, e incluso más allá de los ámbitos nacionales.

Como conclusión, diremos que los resultados comentados sobre el nivel general del razonamiento moral de nuestro grupo de alumnos se ajustan, en términos generales, a las características de los estadios y su evolución descritos por Kohlberg (Hersh, Paolitto y Reimer, 1984; Zanón, 1993; Nuévalos, 1997).

\subsection{Resultados de la intervención}

Al diseñar el programa nos hemos planteado como objetivo intervenir mediante la técnica de "discusión en grupo de dilemas morales" con vistas a estimular el desarrollo del juicio moral de los sujetos participantes. El cuestionario de dilemas sociomorales DIT de Rest ha servido como herramienta de medición objetiva del razonamiento moral en situación de pretest y postest.

Recordemos nuestras hipótesis de partida en las que se afirmaba que esperábamos como fruto de la metodología utilizada un crecimiento del razonamiento moral de los alumnos. Este crecimiento del nivel del razonamiento moral debía manifestarse en un aumento del razonamiento en el nivel posconvencional y la consiguiente disminución en los niveles preconvencional y convencional.

Pasando a los resultados de nuestra investigación y fijándonos en la tabla 8 , pueden verse en las dos columnas del medio los resultados obtenidos por nuestro grupo de Onteniente en los tres niveles, preconvencional, convencional y posconvencional. En la $2^{a}$ columna aparecen los datos obtenidos en el pretest y en la $3^{a}$ los del postest.

Constatamos, en efecto, que en la columna del postest las puntuaciones son inferiores en los niveles preconvencional y convencional. Y, en efecto, de acuerdo también con nuestra hipótesis, en el nivel posconvencional las puntuaciones han ascendido tras la intervención.

En la $4^{\mathrm{a}}$ y última columna se presentan las diferencias obtenidas en los estadísticos de Fisher y Scheffe cuando comparamos el pretest y el postest. Una evolución conforme a lo previsto en las hipótesis podría ser fruto de la evolución natural del pensamiento moral de los alumnos. Para controlar la causa del aumento en las puntuaciones hemos utilizado las pruebas estadísticas de Fisher y Scheffe. Según estos estadísticos, para confirmar que dicha evolución ha sido impulsada por la intervención, las pruebas deben ofrecer un índice de significatividad igual o inferior a 0,05 . 
TABLA 7

PuntUACIONES EN LOS NIVELES DEL DIT EN EL PRETEST Y EL POSTEST, Y DIFERENCIAS SIGNIFICATIVAS

\begin{tabular}{|l|c|c|c|}
\hline Estadio & $\begin{array}{c}\text { Onteniente } \\
\text { pretest }\end{array}$ & $\begin{array}{c}\text { Onteniente } \\
\text { postest }\end{array}$ & Diferencias \\
\hline $\begin{array}{l}\text { Preconvencional } \\
\text { (estadio 2) }\end{array}$ & 8,33 & 6,03 & $0,039^{*}$ \\
\hline $\begin{array}{l}\text { Convencional } \\
\text { (3 y 4) }\end{array}$ & 53,67 & 50,27 & 0,155 \\
\hline $\begin{array}{l}\text { (Posconvencional } \\
\text { puntuacion P\%) }\end{array}$ & 32,49 & 37,84 & $0,029^{*}$ \\
\hline
\end{tabular}

Pueden verse, destacando con un asterisco, los datos que arrojan diferencias significativas. Dichas diferencias las encontramos en el nivel preconvencional y en el posconvencional. Aunque todos los datos se ajustan a nuestras previsiones, las diferencias significativas indican que los cambios obtenidos en los niveles preconvencional y posconvencional se deben al programa de intervención, y no se explican por una pura evolución natural.

También en el gráfico 1 podemos observar las diferencias que se obtienen al comparar los resultados entre el pretest y el postest en los tres niveles del DIT. Con claridad podemos decir que el pensamiento moral posconvencional en el postest ha crecido tras la intervención. Por el contrario, los porcentajes del pensamiento preconvencional y convencional han decrecido. Ambas tendencias se corresponden con nuestras expectativas y con la teoría de Kohlberg que prevé un aumento en el razonamiento posconvencional como consecuencia de exponer a los alumnos al debate de dilemas morales.

GRÁFICO 1

DATOS DE LOS NIVELES DEL DIT EN PRETEST Y POSTEST
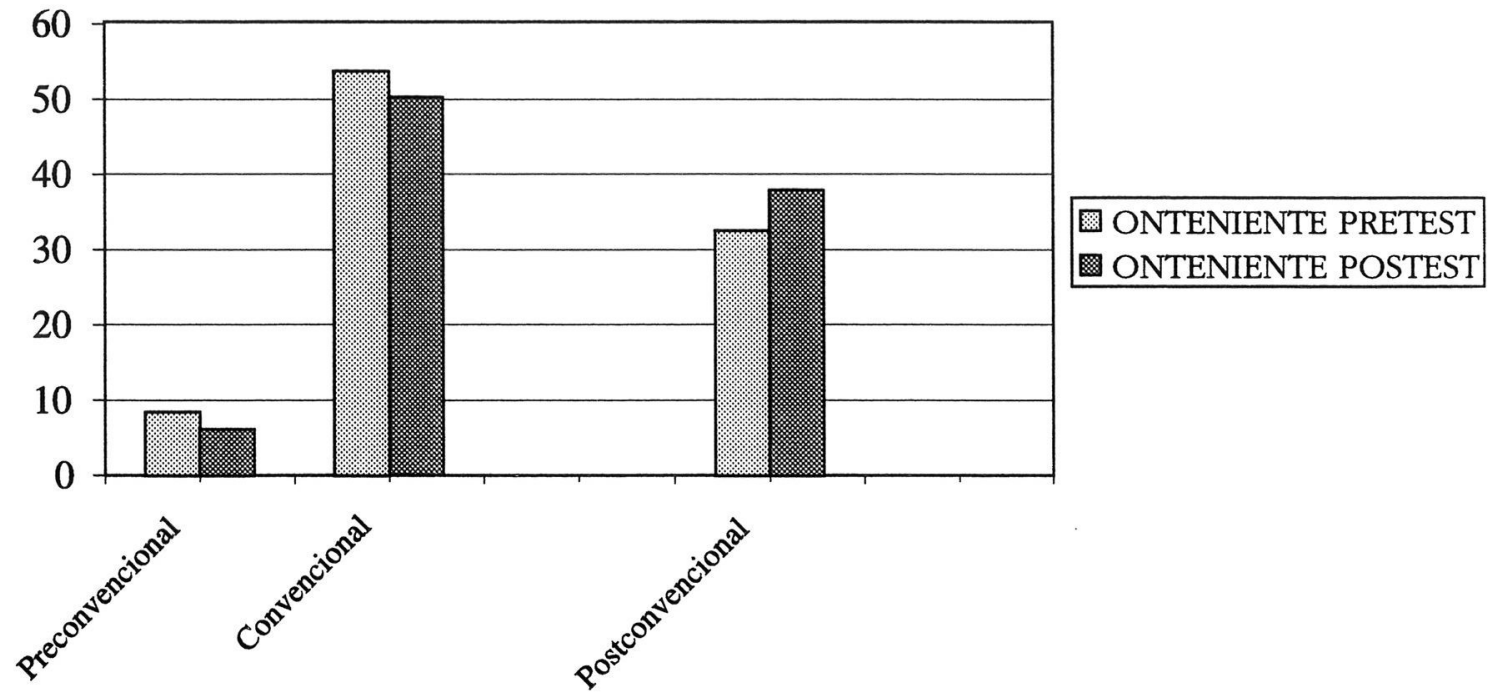
Pasamos ahora a un análisis más minucioso según los estadios. Decíamos que en el DIT el pensamiento posconvencional viene expresado en el índice $\mathrm{P} \%$, que integra la suma de los estadios 5A, 5B y 6 ; el nivel convencional incluye los estadios 3 y 4; por último, el nivel preconvencional está integrado por el estadio 2. Consecuentemente, lo que se esperaba como fruto de la intervención era específicamente un aumento de las puntuaciones en los estadios 5A, 5B y 6, y una disminución paralela en los estadios 2,3 y 4 . En la tabla 9 vemos que esta relación inversa entre los niveles y estadios se da de forma clara, en todos y cada uno de los estadios y conforme a las hipótesis planteadas. En efecto las puntuaciones en los estadios 2,3 y 4 han disminuido respecto al pretest. Una dirección inversa siguen las puntuaciones en los estadios 5A, 5B y 6, que son más elevadas en el postest.

En la última columna de la tabla aparece la significatividad cuando comparamos los estadios en el pretest y el postest. Como ya se vio, las diferencias significativas se sitúan en estadios de los niveles preconvencional y posconvencional. De todos ellos vemos que el estadio 5B, uno de los tres estadios componentes del nivel posconvencional, es el que arroja diferencias estadísticamente más significativas $\left(, 003^{*}\right)$. También la puntuación $\mathrm{P}$ suma de los estadios posconvencionales ofrece significatividad $\left(, 029^{*}\right)$. Y, por último, vemos que en el estadio 2 también se han alcanzado diferencias significativas $\left(, 039^{*}\right)$. En los estadios 3 y 4 , que integran el nivel convencional, no aparecen diferencias significativas entre el pretest y el postest.

\section{TABLA 8}

PUNTUACIONES EN LOS ESTADIOS DEL DIT EN EL PRETEST Y EL POSTEST, Y DIFERENCIAS SIGNIFICATIVAS

\begin{tabular}{|l|c|c|c|}
\hline Estadio & $\begin{array}{c}\text { Onteniente } \\
\text { pretest }\end{array}$ & $\begin{array}{c}\text { Onteniente } \\
\text { postest }\end{array}$ & $\begin{array}{c}\text { Diferencias } \\
\text { significativas }\end{array}$ \\
\hline Estadio 2 & 8,33 & 6,03 & $0,039^{*}$ \\
\hline Estadio 3 & 28,19 & 26,67 & 0,435 \\
\hline Estadio 4 & 25,48 & 23,59 & 0,446 \\
\hline Estadio 5A & 21,73 & 23,59 & 0,372 \\
\hline Estadio 5B & 7,91 & 11,10 & $0,003^{*}$ \\
\hline Estadio 6 & 2,84 & 3,13 & 0,729 \\
\hline Puntuacion P\% & 32,49 & 37,84 & $0,029^{*}$ \\
\hline
\end{tabular}

Así pues, nuestros datos confirman una relación opuesta de las puntuaciones en todos los niveles y en todos y cada uno de los estadios según se había previsto al iniciar la intervención. La dirección de los datos de acuerdo con la hipótesis de partida queda bien ilustrada en el gráfico 2, en la que aparecen representados los datos obtenidos por el grupo de alumnos en los estadios del DIT, en el pretest y el postest. Puede observarse una clara línea descendente en los estadios que integran 
los niveles preconvencional (2) y convencional (3 y 4). La trayectoria inversa en los estadios 5A, 5B y 6, que integran el nivel posconvencional, es también evidente en las barras del gráfico. Todo ello, y como se ha dicho, sigue una dirección de acuerdo con las hipótesis de partida.

Aunque las diferencias no se muestran estadísticamente significativas en todos los estadios, sí pueden considerarse relevantes, puesto que se da un aumento muy significativo en el estadio 5B, que es la causa del aumento también significativo en el nivel posconvencional manifestado en la puntuación P. Como dijimos, la puntuación $\mathrm{P}$ mide los estadios posconvencionales en conjunto (suma de los estadios $5 \mathrm{~A}, 5 \mathrm{~B}$ y 6). Esta puntuación se considera la más importante porque el DIT está especialmente confeccionado para detectar el pensamiento posconvencional. Sólo indirectamente este cuestionario nos informa del pensamiento convencional y preconvencional, es decir, de los niveles y estadios inferiores (Pérez-Delgado, Mestre Escrivá, Frías Navarro y Soler Boad, 1996).

Recuérdese que nuestra hipótesis de partida suponía una relación o movimiento inverso entre los niveles preconvencional y convencional, por un lado, y el nivel posconvencional, por otro. $\mathrm{Al}$ respecto hay que añadir que el incremento en el nivel posconvencional șe nutre obviamente de la disminución en los niveles preconvencional y convencional. Nuestros sujetos han disminuido en la elección de argumentos preconvencionales de modo significativo y la disminución en los niveles convencionales sigue una orientación conforme a la hipótesis, pero no ha sido relevante en términos estadísticos.

GRÁFICO 2

DATOS EN LOS ESTADIOS DEL DIT EN PRETEST Y POSTET

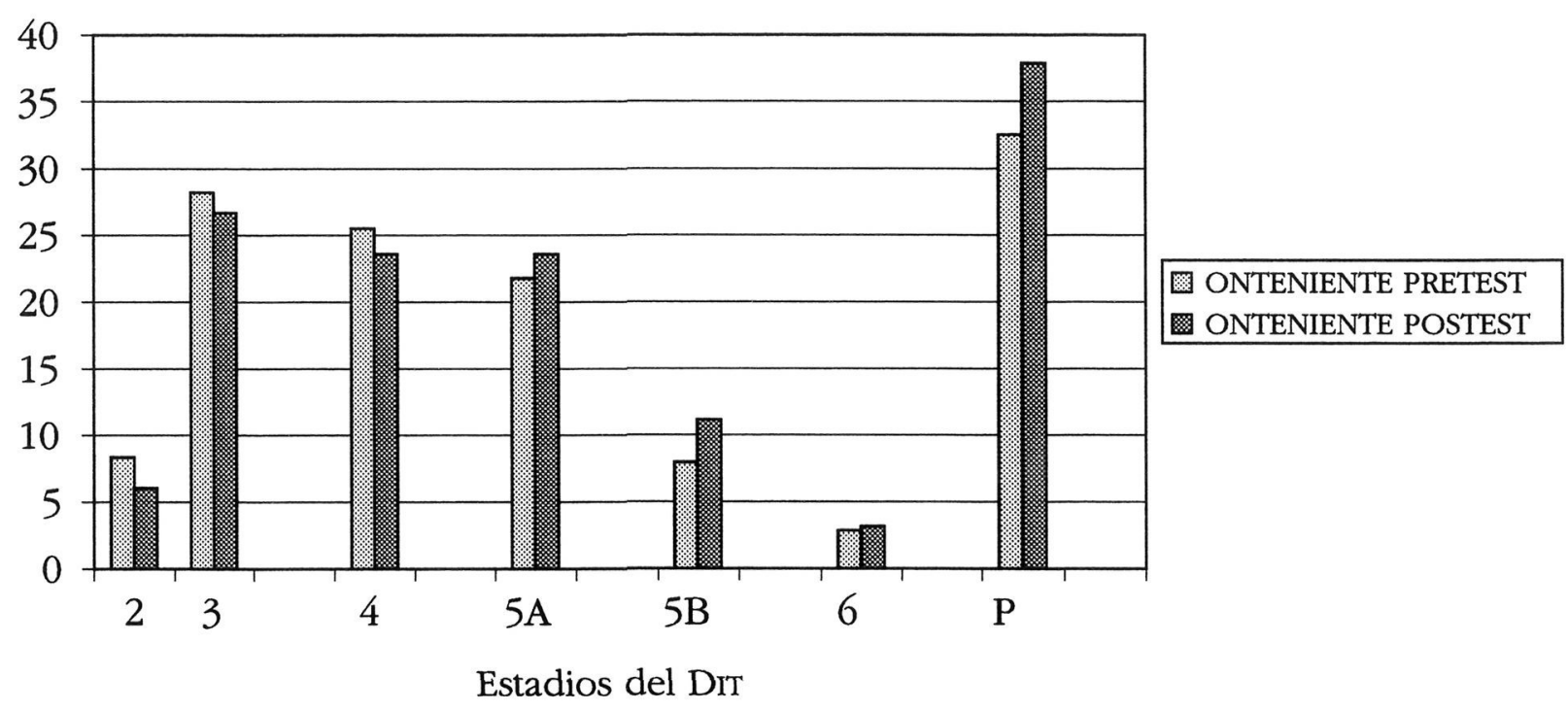


Podemos concluir diciendo que nuestra hipótesis ha sido confirmada con los resultados obtenidos. Por ello afirmamos que los alumnos, al finalizar la intervención, son más posconvencionales. Ello significa que, tras haber participado en el programa, los jóvenes utilizan más los razonamientos morales de principios para resolver dilemas morales que al inicio de la intervención.

\subsection{Discusión de los resultados y conclusiones}

En el análisis de los resultados de nuestra intervención hemos comprobado que los alumnos de Onteniente han realizado una evolución de conjunto trasladando la elección de ítems desde los niveles del pensamiento convencional y preconvencional en el pretest al nivel posconvencional en el postest. Por tanto, y en líneas generales, las hipótesis de partida han sido avaladas en nuestro trabajo y podemos afirmar que, en efecto y según indican nuestros datos, como consecuencia de la aplicación del programa, se ha producido una evolución significativa en el juicio moral de los sujetos participantes. El crecimiento del nivel de pensamiento moral se ha manifestado en un incremento significativo del razonamiento en el nivel posconvencional. Este aumento ha conllevado una disminución paralela en los niveles preconvencional y convencional.

Con todo, el dato más destacado y significativo de este trabajo es la transferencia del estadio 2 del nivel preconvencional al estadio $5 \mathrm{~B}$ del nivel posconvencional. Veamos de modo más específico cuáles son los ítems que recogen, por una parte, el estadio 5B del DiT y que, por tanto, son los ítems que los alumnos han tendido a seleccionar en el postest con resultados significativos. Y paralelamente qué ítems incluye el estadio 2 del DIT y que han sido los que los alumnos han tendido a rechazar de forma significativa en el postest.

TABLA 9

ÍTEMS QUE INTEGRAN EL ESTADIO 5B Y EL ESTADIO 2 EN EL DIT

Ítems que recoge el estadio 5B del DIT

- ¿Los estudiantes siguen principios que ellos creen que están por encima de la ley?

- ¿Qué efecto produciría la suspensión del periódico en la educación del pensamiento crítico de los estudiantes y en sus valores?

- ¿Sería coberente con los pensamientos y creencias propias del Sr. Gómez rechazar al Sr. Vargas para el puesto de trabajo?

- ¿Por qué valores se rige el doctor en su propia vida personal? 


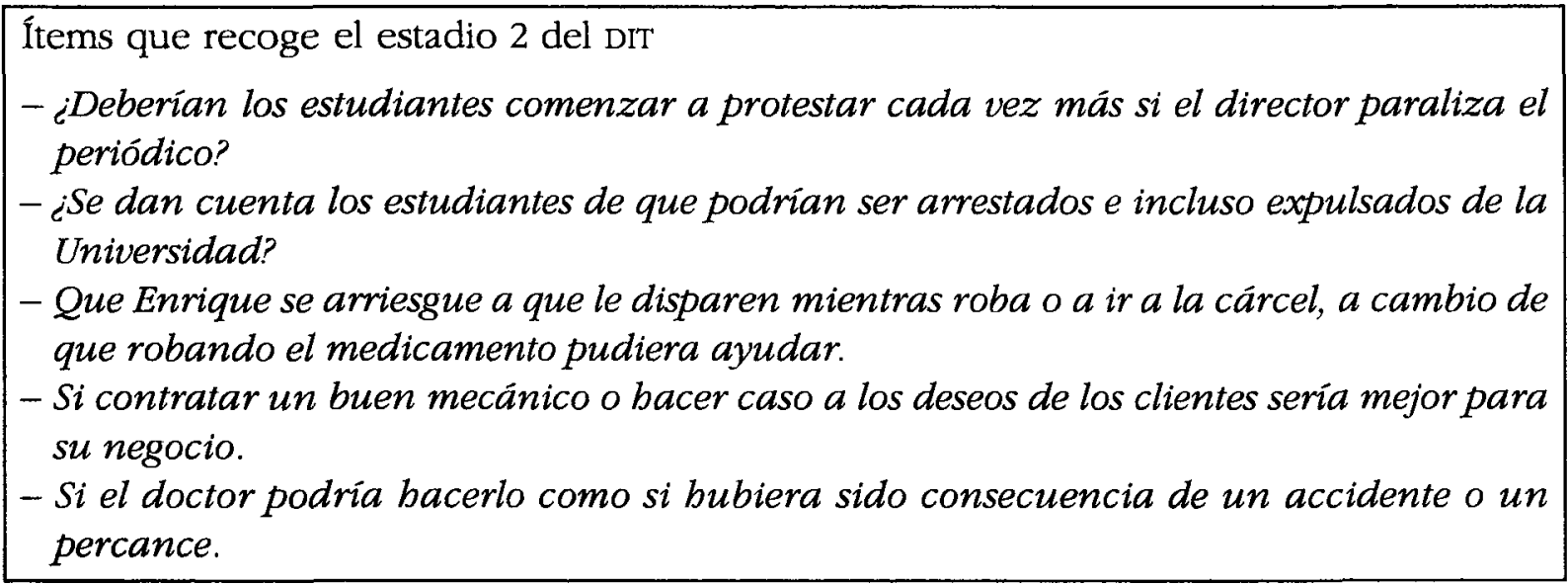

Es decir, tras participar en la intervención, las puntuaciones de los jóvenes del estudio han disminuido significativamente en el estadio 2, pasando de obtener en el pretest 8,33, a obtener 6,03 en el postest. Paralelamente han aumentado sus puntuaciones en el estadio 5B, de obtener 7,91 en el pretest a obtener 11,10 en el postest. Se deduce de esto que los jóvenes testados han abandonado significativamente una perspectiva individualista con vistas a un interés propio inmediato a la hora de afrontar dilemas éticos, al tiempo que ha aumentado su capacidad de emitir juicios morales según una "moral del intuicionismo humanista". Éste es el cambio estadísticamente más relevante de todos los que hemos conseguido con la aplicación del programa.

Está claro que el movimiento evolutivo del pensamiento moral de los sujetos ha seguido una trayectoria que se ajusta a las previsiones. Podemos plantear, sin embargo, a la vista de los resultados, "ipor qué las puntuaciones significativas se sitúan en el nivel preconvencional y posconvencional, y no en el convencional?". Es más, posiblemente lo que más nos llama la atención es que la madurez se haya manifestado de modo más contundente en estadios extremos. El estadio 2 es el inferior y el estadio 5B es uno de los dos superiores.

Una posible explicación podría ser que los sujetos que componen nuestro grupo tienen una media de edad cronológica superior a la que corresponde al nivel de estudios ( $2^{\circ}$ de Magisterio) y esto podría implicar una mayor solidez en sus niveles de razonamiento convencional, ya que no están afectados por una etapa evolutiva de transición como es la adolescencia.

Dada la composición de la muestra en términos numéricos (sólo 23 alumnos) puede decirse que la intervención ha tenido un grado muy alto de eficacia. Estos óptimos efectos de nuestra intervención pueden ser atribuidos a diversos factores:

a) Como ya se ha dicho, nuestro grupo tiene una media de edad cronológica superior a la que corresponde al nivel de estudios. Existe, por otra parte, documentación científica para afirmar que los efectos de los programas, cuando se utiliza la técnica del debate de dilemas, es mayor en grupos de adultos. 
Un punto de especial interés resulta comprobar en qué niveles de edad resulta más productiva la acción educativa en esta área. Con el objeto de constatar los efectos diferenciales de las intervenciones sobre el desarrollo del juicio moral en función de la edad... En las comparaciones con los grupos control, se observa que los efectos de mayor magnitud ocurren en el grupo de adultos, seguido, a cierta distancia, por el resto de los niveles considerados (Pérez-Delgado y Mestre Escrivá, 1995, 171-172).

b) Por otro lado, la participación voluntaria estuvo garantizada, ya que el grupo de alumnos fue consultado acerca de la aplicación del programa y aceptaron todos de buen grado. Podemos hablar de un alto grado de motivación intrínseca que ha manifestado este grupo de alumnos a lo largo de todo el curso y de modo singular durante el programa. Testimonios de los mismos alumnos al final del programa dan a entender, en efecto, que disponían de una motivación intrínseca para el "crecimiento personal" en general, y en concreto para el desarrollo moral. Para apoyar esta opinión nuestra, pueden verse ejemplos semejantes en la tabla 10 sobre el testimonio de algunas alumnas sobre su experiencia con los debates. Por supuesto, los ejemplos que se presentan son sólo una selección, en las consultas llevadas a cabo con estrategias cualitativas este criterio era compartido por la mayoría de la clase.

Una conclusión al respecto es que sería necesario investigar acerca de la influencia de los factores emocionales en el razonamiento moral; un programa para el crecimiento moral no puede ignorar dichos factores.

c) En nuestra opinión, otro elemento que ha podido influir positivamente y que debería tenerse en cuenta es el hecho de que en la etapa adulta el pensamiento formal está más consolidado. Puede presuponerse que existe un entrenamiento cognitivo y una maduración global que podría facilitar una evolución cognitivo-moral más rápida.

d) Otro factor a tener en cuenta es el efecto que pueda tener la explicación de la teoría de Kohlberg en el programa de intervención moral. A los alumnos se les explicó dicha teoría así como la descripción de los estadios y el funcionamiento de la técnica de discusión de dilemas sobre el razonamiento moral. Además se llevaron a cabo dos prácticas para la discriminación de los argumentos según niveles de razonamiento moral.

$\mathrm{Al}$ respecto, diversos autores han planteado dos posturas. Por un lado, la de considerar que por este procedimiento el conocimiento de la teoría podría contaminar el postest. Por otra parte, se puede argumentar que la exposición a la teoría es un instrumento educativo para cambiar el pensamiento moral de la persona a la que se instruye.

Desde esta segunda postura la instrucción teórica facilitaría la reorganización cognitiva, clarificando y concienciando sobre los niveles en que se fundamentan los argumentos, poniendo de manifiesto más conscientemente la incoherencia de argumentos de bajo nivel moral. En tal caso el aumento de las puntuaciones en el 
postest sería un indicador verdadero del desarrollo del razonamiento moraln (Pérez-Delgado y Mestre Escrivá, 1995, 171-172).

En nuestra opinión, la instrucción teórica no ha conducido a un aumento artificial del pensamiento moral de los alumnos. Probablemente la mejor prueba de ello sean las opiniones de los mismos alumnos recabadas a partir de diferentes pruebas de evaluación cualitativa. En ellas se puso de manifiesto que los jóvenes realizaron durante la intervención un aprendizaje significativo y vital. Pueden verse en la tabla 10 algunos ejemplos de sus testimonios.

TABLA 10

EJEMPLOS DE APRENDIZAJE ADULTO REALIZADO EN CLASE POR LAS ALUMNAS

Actividad 3. Características del aprendizaje adulto: Pon algún ejemplo de aprendizaje adulto que has realizado en clase.

Begoña Gil: "Una de las cosas que más me ha gustado, porque me ha ayudado a preguntarme por la introspección, ha sido las técnicas que hemos trabajado en clase sobre los dilemas.

El hecho de ponerme conscientemente en cada situación planteada, teniendo que poner a flote unos valores y decidir sobre la importancia de unos sobre otros, y dar respuesta clara y decidir en unas ocasiones, e insegura y confusa en otras, me ha ayudado a despertar de forma más clara mi capacidad de interrogarme y hallar respuesta respecto al sentido de la vida, teniendo una percepción del mundo y de la existencia más humanitaria y global...

Además de este elemento, también se ha despertado en mí de forma más intensa la empatía, y un sentido más crítico de la libertad junto con la responsabilidad. Estos tres elementos han sido los más importantes en el desarrollo de la asignatura".

María de la Fe Bañuls: "De la asignatura puedo decir que he aprendido muchas cosas. He aprendido a ver las cosas desde otros puntos de vista, es decir, a ponerme en el lugar de otro. Algunas veces, después de presenciar debates y luego las reflexiones, al llegar a casa me he puesto a reflexionar sobre la clase y siempre he acabado aplicándolo a algún aspecto de mi vida o a la de alguna amiga; lo más curioso es que en algunos casos no veía solución y he salido del paso, pero lo mejor es que luego me he sentido muy bien.

Pero lo más significativo que he aprendido de la asignatura es el aprender a ver lo que realmente me importa. En algunas situaciones un tanto difíciles he aprendido a exteriorizar mis sentimientos, a diferenciar lo que deseaba y lo que realmente quería. Por ejemplo...".

Marta Bataller: "A través de los temas que hemos tratado con los dilemas he aprendido cosas que luego puedo aplicar a mi vida. A través de los dilemas me he llegado a plantear cosas que de otro modo no hubiera hecho".

Eva Frutos: "A veces hemos tenido que diferenciar entre lo que está bien y lo que está mal, sabiendo lo que haces y pensando en ti y en los demás; mostrar tus valores o los que crees que son fundamentales en tu vida. Pero sobre todo siendo auténticos". 
Queda claro en estas opiniones que las jóvenes realizaron durante la intervención un aprendizaje significativo y vital. Así, por ejemplo, cuando la alumna dice: "...He aprendido a ver las cosas desde otros puntos de vista, es decir, a ponerme en el lugar de otros. Algunas veces, después de presenciar debates y luego las reflexiones, al llegar a casa me he puesto a reflexionar sobre la clase y siempre he acabado aplicándolo a algún aspecto de mi vida o a la de alguna amiga...". Este comentario ilustra cómo la alumna en cuestión ha realizado ejercicios cognitivoempáticos provocados por los dilemas y debates, y que además, y esto nos parece muy relevante, estos ejercicios le han llevado a modificar su modo de ver algunas cosas adoptando la perspectiva de otros e incluso le ha servido para aplicarlo en su propia vida. Es más, no sólo ha realizado un aprendizaje vivencial, útil para sí misma, sino que también ha encontrado algún tipo de utilidad para los problemas o la vida de "alguna amiga».

Los espontáneos y refrescantes testimonios de las alumnas apoyan la idea de que existen unos vínculos entre las diferentes dimensiones de la moralidad humana, en este caso razonamiento ("al llegar a casa me he puesto a reflexionar"), comportamiento ("he acabado aplicándolo a algún aspecto de mi vida") y emociones ("He aprendido ... a ponerme en el lugar de otro" o bien "he aprendido a exteriorizar mis sentimientos, a diferenciar lo que deseaba y lo que realmente querían). Una consecuencia de ello puede ser que razonar sobre dilemas morales no sólo contribuye a que la persona se sitúe intelectualmente en la postura de otro, sino que además estimula las emociones empáticas porque le incita a imaginar lo que sienten las personas involucradas en el dilema.

Hoffman realiza un análisis acerca de la vinculación entre los principios morales con la empatía, y de la contribución de ésta al razonamiento y al juicio morales.

Si se activa un principio moral lleno de afecto empático, éste tiene el efecto de aumentar o reducir la intensidad de la aflicción empática del observador... ¿Qué obtienen los principios morales del vínculo con la empatía? Mi hipótesis es que a los principios morales abstractos, aprendidos en contextos didácticos "en frío", les falta fuerza motivacional. La contribución de la empatía a dichos principios es que los convierte en cogniciones prosociales cálidas (representaciones cognitivas llenas de afecto empático que les dan por tanto fuerza afectiva... la concurrencia de la empatía y el principio crea un vínculo entre ambos que llena a éste de afecto).

Resumiendo, mi hipótesis es que, cuando los principios se asocian con el afecto empático, se llenan de afectividad, adquieren simultáneamente la cualidad motivacional del afecto y se guardan en la memoria como representaciones prosociales llenas de afecto o en cogniciones prosociales cálidas que se pueden activar al ver la violación de un principio. Una predicción sencilla que se deriva de la hipótesis... es que la empatía y el principio tienen una relación más estrecha con la acción prosocial, juntos que por separado (Hoffman, 2002, 201).

Todos estos ejemplos ponen de manifiesto que no es posible, ni tampoco deseable, aislar totalmente las variables intelectuales de otras variables de tipo personal (emocionales, espirituales, contextuales...). En efecto, para entender los 
procesos de adquisición de la moralidad es mejor observar las historias colectivas en las que participa el sujeto, "el sujeto actuando con otros sujetos en una situación culturalmente diseñada" (Puig Rovira, 2003, 60-61).

Insistimos, no obstante, que el trabajo específico con dilemas se llevó a cabo paralelamente a otro tipo de actividades y reflexiones, como por ejemplo con el visionado de la película I.A. (Inteligencia artificial) en que el tema de debate fue: ¿puede o debe considerarse al "robot David" una persona? El debate fue completado con varias actividades en torno al tema: "Qué significa ser una persona humana".

A todos los componentes personales y contextuales debemos atender en el diseño, aplicación y evaluación de programas, si queremos aproximarnos a un modelo integral que fomente la consistencia entre juicio y acción moral. Diferentes autores reivindican la necesidad de contar con una teoría integral del desarrollo moral que, efectivamente, integre los distintos modelos, planteamientos y aspectos de las teorías parciales (Bronfenbrenner, 1993; Cortés, 2002, 2003). Estos nuevos modelos, sin excluir de su estudio los componentes cognitivos, deben ampliar el campo de estudio al resto de componentes de la persona para superar con enfoques más globales y holistas el reduccionismo racionalista al que las ciencias psicopedagógicas y las del pensamiento han estado sometidas en las últimas décadas. La razón es pilar básico de la persona pero no es el edificio, no es la persona, y la educación se debe a toda la persona.

Finalmente y como conclusión de nuestro estudio, podemos afirmar que este trabajo aporta información empírica de cara a verificar la eficacia de la técnica de "grupos de discusión de dilemas morales" en la estimulación del desarrollo del razonamiento moral. Además, se han ofrecido algunos ejemplos de información cualitativa que refuerza la fiabilidad de los resultados científicos. En nuestra opinión este tipo de información garantiza que la eficacia de un programa no se reduce a la capacidad que mide el cuestionario, en nuestro caso el razonamiento moral, sino que la intervención ha movilizado el sentido moral global de los participantes. Y entendemos que no sólo el sentido moral sino que para algunos de los alumnos nuestro curso sobre educación moral ha estimulado un sentido humano más hondo que apunta, no sólo a una reflexión moral, sino además a una emergencia del deseo inconsciente de un sentido vital.

Sería nuestro deseo adentrarnos en posteriores trabajos en una perspectiva cabal e integral de la pedagogía que atienda a la persona total. A nivel metodológico nos parece esperanzadora la propuesta de Max van Manem que defiende una metodología fenomenológica-hermenéutica para las ciencias humanas:

La ciencia humana fenomenológica es el estudio de los significados vividos o existenciales... es, finalmente, una ciencia "humana", y no una ciencia natural, puesto que el objeto de estudio de la investigación fenomenológica son siempre las estructuras de significado del mundo vivido "humano". De forma opuesta podemos decir que los objetos naturales no viven experiencias de un modo consciente ni significativo... una investigación que tiene "como objetivo último, el cumplimiento de nuestra naturaleza humana: llegar a ser plenamente quienes somos... (la 
fenomenología es un tipo de investigación que busca)... descubrir lo que subyace en el centro ontológico de nuestro ser" (Van Manem, 2003, 29-31).

Tenemos la convicción de que todo programa de educación moral no debe perder de vista este enfoque integral, aunque metodológicamente, de cara a un trabajo de investigación, se haga necesario en ocasiones abordar componentes específicos de la moralidad. Consideramos finalmente que este programa, dirigido de forma muy específica al incremento del pensamiento moral de los alumnos, tuvo una mayor eficacia porque el componente de la moralidad investigado se trabajó al abrigo de una antropología global y una postura holista de la moralidad.

\section{Bibliografía}

Blasi, A. (1980) Bringing Moral Cognition and Moral Action: A critical Review of the Literature, Psychological Bulletin, 88, 1-45.

Bolívar, A. (1995) La evaluación de valores y actitudes. Madrid, Anaya.

CAMPBeli, R. L. (2001) La psicología moral de Piaget en la perspectiva poskohlbergiana, en HaAfTEn, W.; Wren, T. y Tellings, A. Sensibilidades morales y educación, vol. I. Barcelona, Gedisa, 131-161.

CORTÉs, A. (2002) La contribución de la psicología ecológica al desarrollo moral. Un estudio con adolescentes, Anales de psicologia, 17 (2).

EsCámeZ, J. (1999) La formación moral como eje transversal para el siglo xxi. Ponencia en el xxxII Coloquio de Inspectores Europeos de Educación: Los valores en la Europa del siglo XXI. Documento policopiado.

EsCÁmeZ, J. y GiL, R. (2002) La educación en la responsabilidad. Barcelona, Paidós.

HAGNES, F. (2002) Ética y Escuela. ¿Es siempre ético cumplir las normas en la escuela? Barcelona, Gedisa.

HeRSh, R. H.; PAOLITTO, D. P. y ReIMER, J. (1979) El crecimiento moral de Piaget a Koblberg (1 ${ }^{a}$ edición). Madrid, Narcea.

Hoffman, M. L. (2002) Desarrollo moral y empatía. Barcelona, Idea Books.

IBÁÑEZ-MARTín J. A. (2001) El profesorado de Universidad del Tercer Milenio. El nuevo horizonte de sus funciones y responsabilidades, Revista Española de Pedagogía, 220, 441466.

KoHLBerg, L. (1992) Psicología del desarrollo moral. Bilbao, DDB.

Núv́nalos Ruiz, C. (1997) Desarrollo moral y valores ambientales. Departamento de Psicología Básica. Universidad de Valencia. Junio de 1997. (Tesis doctoral dirigida por los Drs. Esteban Pérez-Delgado y Jesús Ballesteros Llompart).

NúvVAlos, C. y BelLVER, V. (1999) Una mirada diferente. La mujer y la conservación del medio ambiente. Valencia, Edetania Ediciones.

Pérez-Delgado, E. y Mestre Escrivá, V. (1995) La medida del desarrollo moral, en Pérez-DelGADO, E. y SOLER, M. J. El cuestionario de problemas sociomorales (DIT) de J. Rest y su uso informatizado. Valencia, Albatros Ediciones, 9-22.

- (1995) El crecimiento moral. Programas psicoeducativos y su eficacia en el aula. Valencia, Universidad de Valencia. 
Puig Rovira, J. M. ${ }^{a}$ (2003) Prácticas morales. Una aproximación a la educación moral. Barcelona, Paidós.

Roche, R. y Sol, N. (1998) Educación prosocial de las emociones, valores y actitudes positivas para adolescentes en entornos familiares y escolares. Barcelona, Blume.

SOBER, E. y WiLSON, D. S. (2000) El comportamiento altruista. Evolución y psicología. Madrid, Siglo XXI.

VAN MANEM, M. (2003) Investigación educativa y experiencia vivida. Barcelona, Idea Educación. Yus, R. (2001) Educación Integral. Una educación bolística para el siglo xxI, vols. I y II. Bilbao, DDB.

\section{ANEXo}

Alumnos participantes en el programa

La autora desea manifestar su reconocimiento y sincera gratitud a todos los alumnos estudiantes de $2^{\circ}$ curso de Magisterio durante el curso 2002-2003 de Onteniente participantes en el programa y verdaderos protagonistas de la experiencia; no le cabe duda de haber tenido la suerte de trabajar con un grupo de alumnos de excepción.

Al finalizar el programa y tras ser consultados, el grupo de alumnos manifestó su deseo de aparecer con sus nombres completos en la publicación. Aunque no es lo común en este tipo de publicaciones, consideramos justo que aparezcan los verdaderos autores del programa:

Rebeca Agullo Segui, M. Estela Alhambra Reig, Matías Arrue Balbastre, M. ${ }^{a}$ de la Fe Bañuls Gil, Carolina Bañuls Pastor, Marta Bataller Montes, Silvia Blanes Ivorra, Jessica Botella Beneyto, Leonor Breso Rodríguez, M. Jesús Bustos Mejias, Verónica Castañer Puig, Arantxa Català Miñana, Ana María Company Segui, M. ${ }^{a}$ Ampar Donat Belda, German Estévez Abad, Eva M. ${ }^{a}$ Frutos Domínguez, Begoña Gil Castello, Ana Gomis Fuentes, M. Salud López Llobell, Erika López Martín, Ruth Marti Molla, M. ${ }^{a}$ Ángeles Martínez Mompo, Ana María Mompo Ferrer, Celia Montoya Anaya, Sara Morales Guillem, Eva María Peñalva España, Noemí Perez Cloquell, Esmeralda Pérez Serrano, María Teresa Rodríguez Barbe, Carmen Roig Soria, Llanos Sanchís Monte, Eva Sandín Cortés, Ana Isabel Santarromana, Rosario Sempere Domingo, Javier Solano Sánchez, M. ${ }^{a}$ Andrea Soler Sanchís, Virginia Tomás López, M. ${ }^{a}$ Carmen Penedes Reig. 